\title{
GEOMATICS IN BRIDGE STRUCTURAL HEALTH MONITORING, INTEGRATING TERRESTRIAL LASER SCANNING TECHNIQUES AND GEOTECHNICAL INSPECTIONS ON A HIGH VALUE CULTURAL HERITAGE.
}

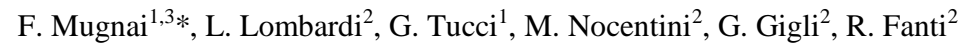 \\ ${ }^{1}$ DICEA - Dept. of Civil and Environmental Engineering, University of Florence, Via di S. Marta 3, 50139 - Florence, Italy - \\ francesco.mugnai@ec.europa.eu,grazia.tucci@unifi.it \\ ${ }^{2}$ Department of Earth Sciences, University of Florence, Largo Enrico Fermi 2, Arcetri, 50125, Florence,Italy - luca.lomardi@unifi.it, \\ massimiliano.nocentini@unifi.it, giovanni.gigli@unifi.it, riccardo.fanti@unifi.it \\ ${ }^{3}$ European Commission, Joint Research Centre (JRC), Directorate A, Scientific Development Unit - francesco.mugnai@ec.europa.eu
}

KEY WORDS: Terrestrial Laser Scanning (TLS), Cultural Heritage (CH), Bridge Structural Monitoring, Surface Comparison

\begin{abstract}
:
The paper presents preliminary findings from a research study designed to assess the health status of a medieval bridge built on 1500 under the Medici dynasty over the river Sieve, close to Florence. The structure, a two span stone bridge with a main central pillar, experienced some restructuring interventions from 1555 to the present. The left span has been closed for some decades, and for many years the water has been allowed to float under it in case of severe flood only. At the beginning of year 2000 the left span has been opened to the regular flux of water. After opening, a maelstrom has been noticed as permanently present at the main pier's basis highlighting the presence of a fracture in the concrete base around the central pile of the bridge. In order to investigate structural health and to assess bridge's stability structural inspections and hydraulic surveys have been carried out. This manuscript reports Terrestrial Laser Scanning (TLS) survey results. Surface comparisons to identify anomalies and defromations have been carried out by exploiting Two TLS campaigns that were performed within a 6 years time span.
\end{abstract}

\section{INTRODUCTION}

\subsection{Applying 3D technologies to Cultural Heritages (CH)}

In the latest years, the development of 3D technologies applied to the $\mathrm{CH}$ field has led to results of utmost importance from the point of view of preservation, development, communication and fruition of our assets (Bitelli, 2017). The 3D modelling of Cultural Heritage is now mainly based on digital techniques to produce complete three-dimensional surveys (Tucci, 2011). Laser scanner data availability is increasing rapidly, the attention and interest for technical application is growing in the same way. Most advanced 3D models, which mainly consist of point-cloud data, are strongly exploited by engineers, both for research and industrial purposes.

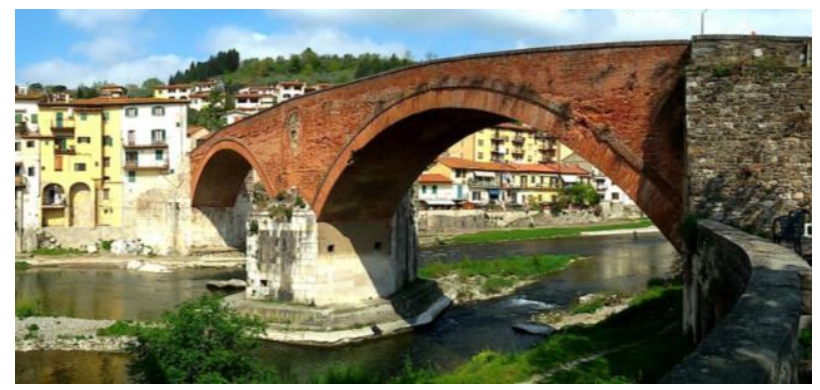

Figure 1 - View from the right side of the bridge, current state.

Technicians and researchers, who need to work on spatial data, intensively look and work for technical and methodological improvements. Additionally, local authorities, agencies and supranational institutions caring about $\mathrm{CH}$ conservancy, need updated and broad databases on territorial scale for planning of interventions and for preventing protracted damages to $\mathrm{CH}$. (Korumaz, 2017). The case study reported in this paper, is an effective example of Terrestrial Laser Scanning (TLS) application, which among others, permits to compare geometric settings within a several years time span; and can be considered as a long period structural health monitoring.

\subsection{Study case}

As a matter of facts, the Pontassieve bridge (Fig. 1) has experienced many restoration interventions during the past years, having the opportunity to build a long period monitoring would therefore permit to assess the bridge's structural health in a more comprehensive way. In detail, after a few years of inactivity, the left span bridge's has been opened to the regular flux of water. Immediately after, a maelstrom (Fig. 2) has been noticed as permanently present at the main pier's basis highlighting the presence of a fracture in the concrete base around the central pile of the bridge.

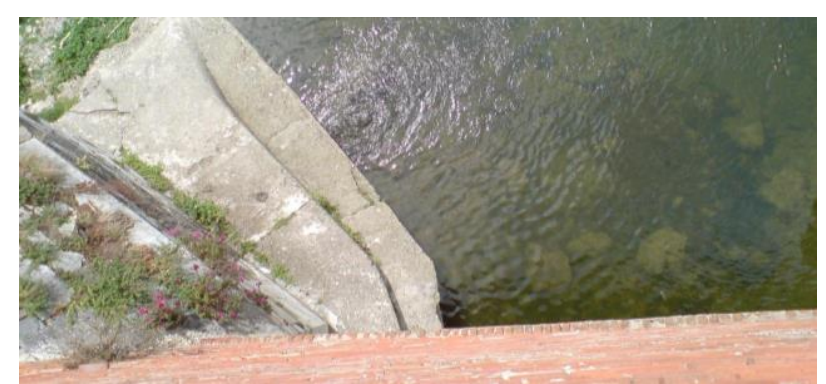

Figure 2 - View from the top of the bridge of the emerging

\footnotetext{
* Corresponding author
} 
The flux of water is the offshoot of a current that comes out of the basement itself and that, joining the Sieve in its natural path, rises towards the surface of the water creating this turbulence effect. Over the years (local people have asserted that this phenomenon has been visible since the 1990s) the current has been dug into the basement and started a process of erosion, which could easily lead to undermine the stability of the entire bridge's structure.

\section{METHODS}

\subsection{Techniques}

Geometry, boundary conditions and material properties are some of the elements that characterize the vast and heterogeneous complexity of Historical structures (Castagnetti, 2012).

Performing survey, inspections and related monitoring, are considered as main instruments to acquire overall and detailed historical architecture's understanding (Tucci, 2016). TLS could give a precious support in reducing time and efforts of user for reproducing the complex geometries.

Determining vulnerability of buildings, especially in case of ancient structures like the Pontassieve bridge, is one of the main application field of such an advanced technique like TLS. In order to obtain reliable results from geometric analysis high accuracy metric survey are crucial. TLS provides detailed 3D models capable to report complex architecture for different purposes, such as: photorealistic representations, historical documentations, or risk assessment analyses aimed to verify the effects resulting from progressive damages or from the onset of new damages (Fergonese, 2017). The high resolution of laser scanning survey permits to extract even the smallest and detailed features, namely crack opening directions, structural crack patterns, (Gigli, 2009), and orientation of rock mass's critical discontinuities (Gigli, 2011).

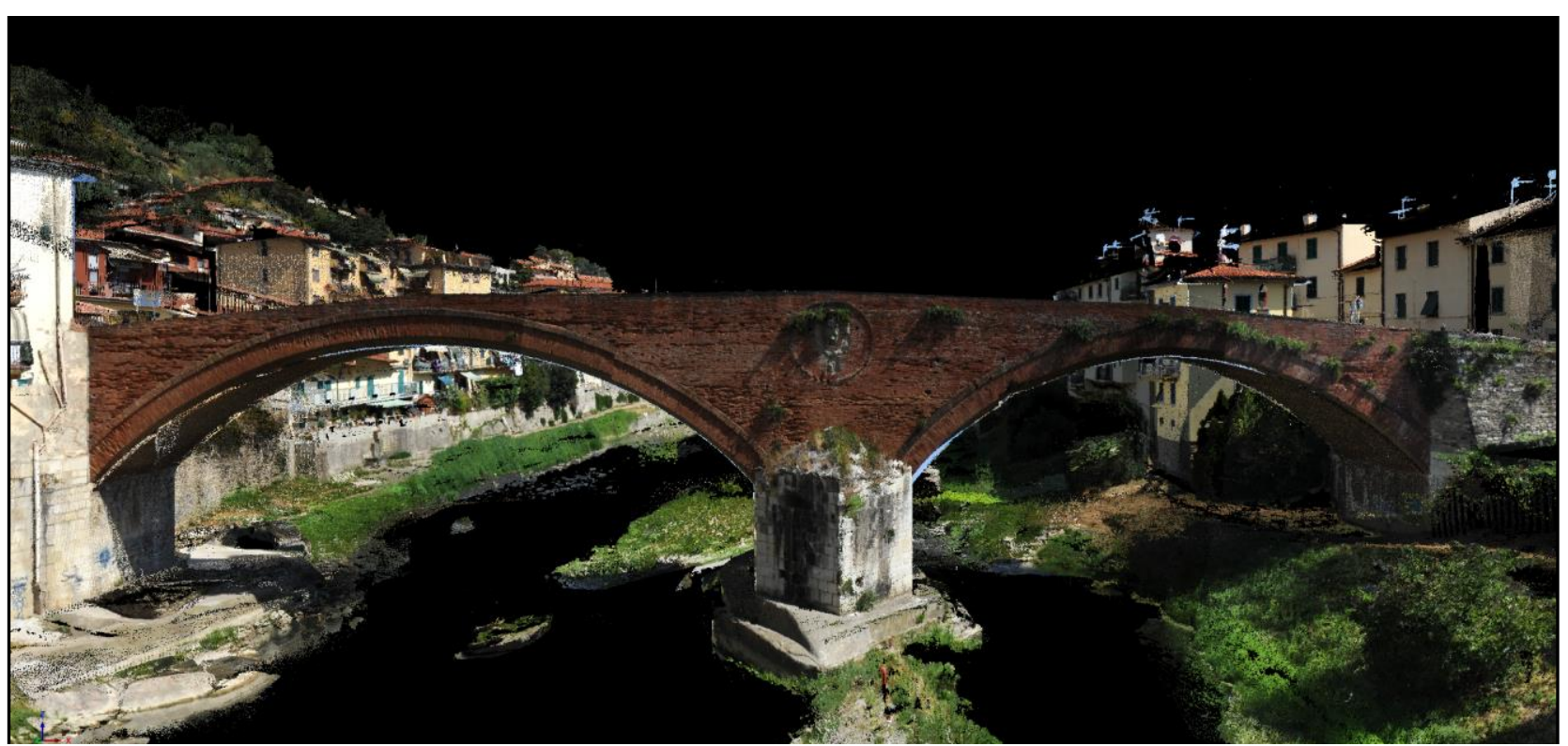

Figure 2 - Pontassieve bridge's coloured 3D point cloud. south view.

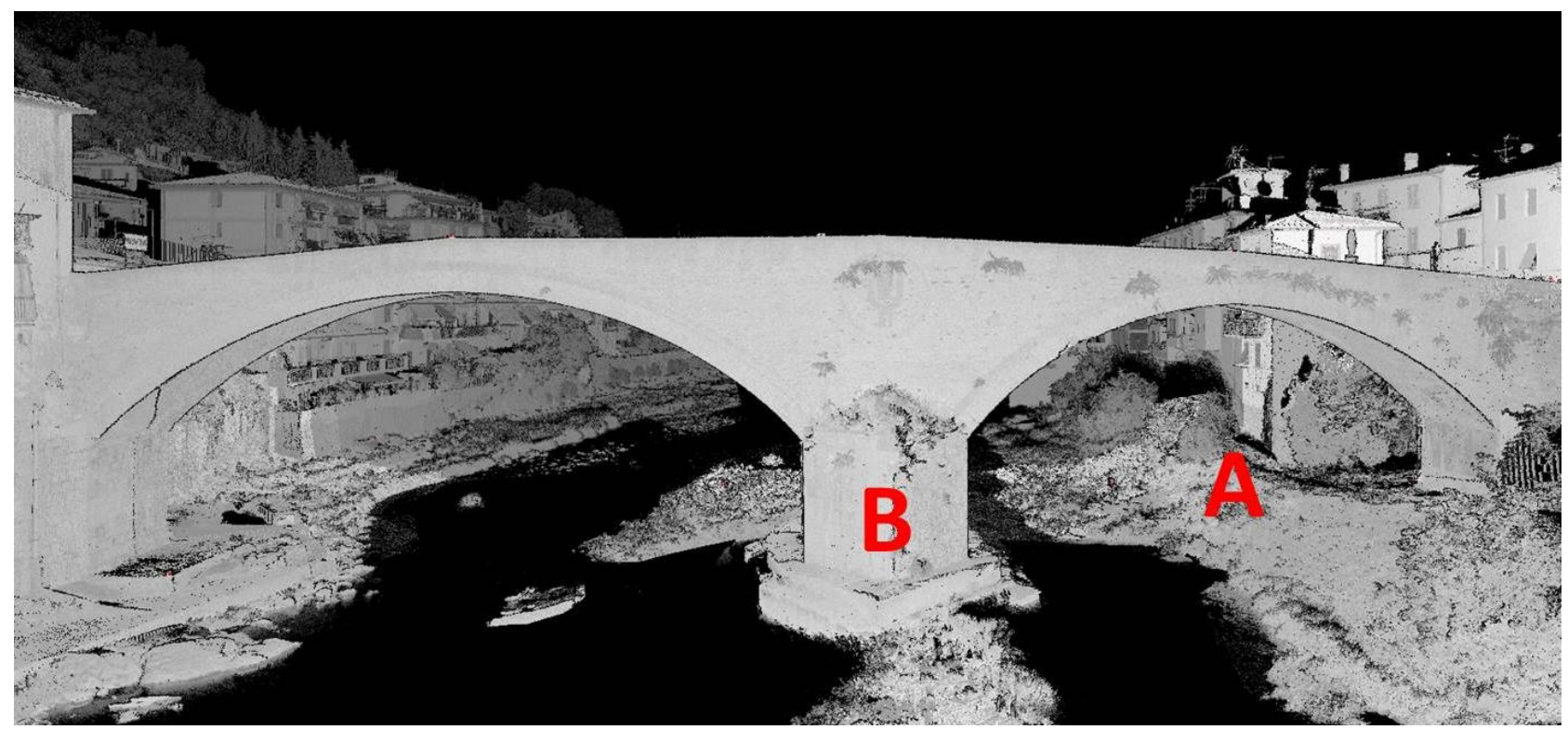

Figure 3 - Merged Point cloud from 2017 Laser Scanner campaign. A) Left span. B) Central Pillar. 


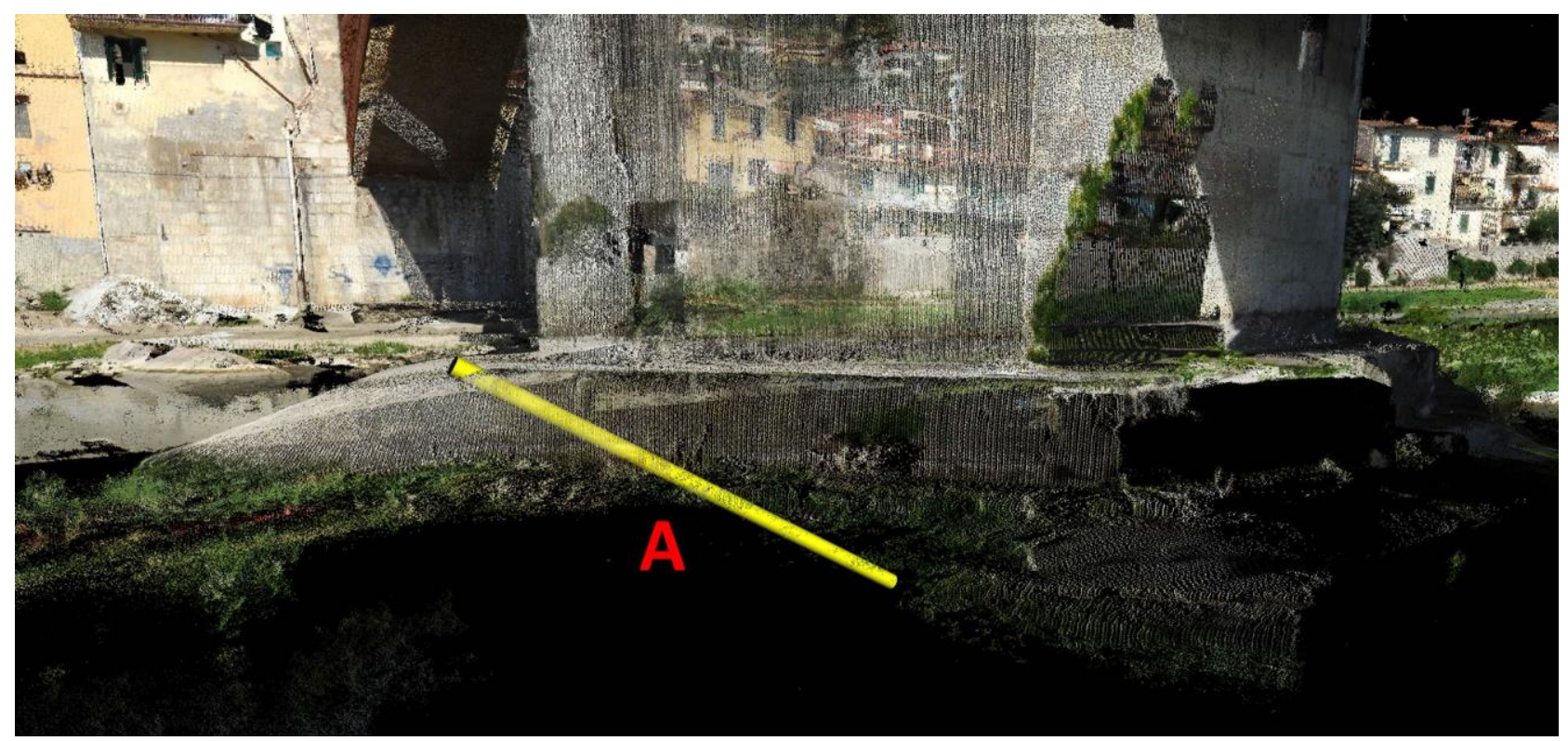

Figure 4 - Visualization of the Inclined borehole (a) on the central pillar's coloured point cloud. Inspection detected a vacuity inside the pillar structure.

TLS acquires high-resolution data sampling of the observed object surface with an accuracy of millimetre. The experiences of last decades proved that traditional survey techniques are not able to provide the required accuracy, to limit the in-situ survey time and to reach the level of detail needed for the digitalization of cultural heritage (Tucci, 2018). TLS can also provide precise geometric survey in order to know the buildings in details with all deformations and anomalies (crack movements, surface deformations, material, etc. (Pesci, 2015) In order to evaluate the incidence of the turbulent water flow on the bridge stability and to assess the health status of the bridge's structure, structural and geotechnical inspections, and two Terrestrial Laser Scanning campaigns have been performed.

The inspection campaign consisted both of a vertical borehole inspection, conducted in the bedrock underlying the main pillar, and of an inclined borehole (Fig. 3) conducted through the pillar structure.

Some inspections have also been carried out to investigate the impact of water flux on the basement of the main pillar. Chemical tracers, have been employed with the goal of identifying source and pathway of the water flux that nurtures the turbulence. Using both dissolved salts and fluorescent dyes techniques.

\subsection{Terrestrial Laser Scanner survey}

TLS survey campaigns have been designed to monitor bridge's stability and deformations over a time span of 7 years. On one hand a point cloud of the bridge structure has been acquired and elaborated on year 2017, on the other hand the same dataset has been compared with an older dataset acquired on year 2010 . Though the comparison of the two laser scanner acquisitions has been partially performed at this stage of the monitoring campaign, the accuracy and resolution levels of both point cloud datasets, together with a precise global referencing of the laser scans, have been set to detect potential differential displacements and to pinpoint hidden structural joints.

The comparison between 2011 and 2017 points clouds have been carried out using both automatic and manual techniques. One of the two point clouds was not geo-referenced during the acquisition campaign, to superimpose the two point clouds an automatic detection algorithm has been used. However, to avoid misleading results, the automatic detection and coupling of the two point clouds has been processed on the bridgeheads only, without manipulating the central part of the bridge, that represent the core subject of the study case and has to be investigated. Figure 4 shows 3D mesh that has been generated from point clouds.

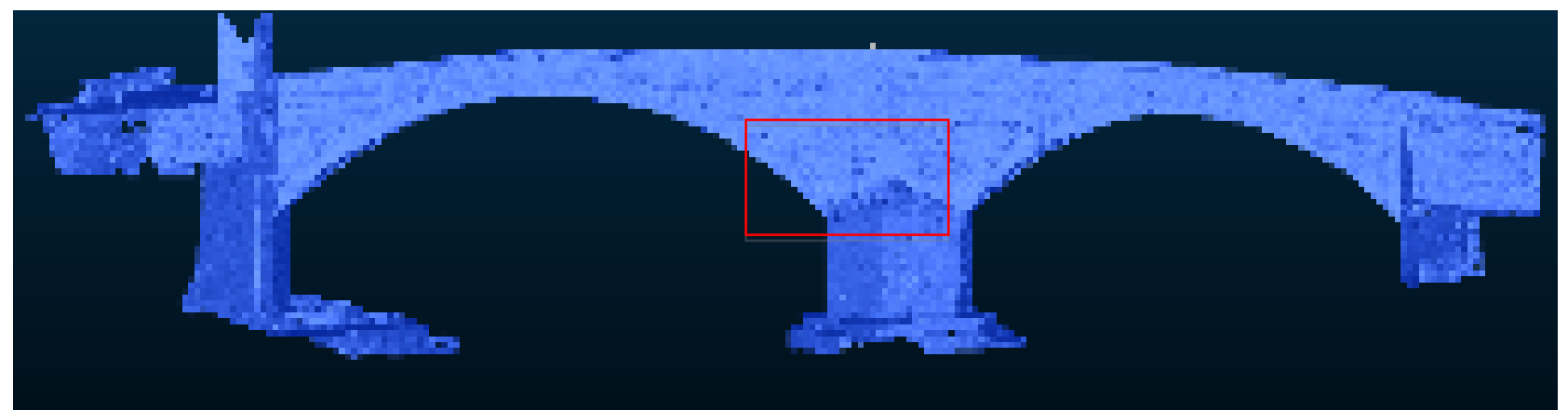

Figure 4 -3D mesh of the bridge obtained from point cloud by applying the following parameters: Octree depth $=14$, Samples per node $=4$, Full depth $=8$, Point weight $=12$, Boundary $=$ Dirichlet 


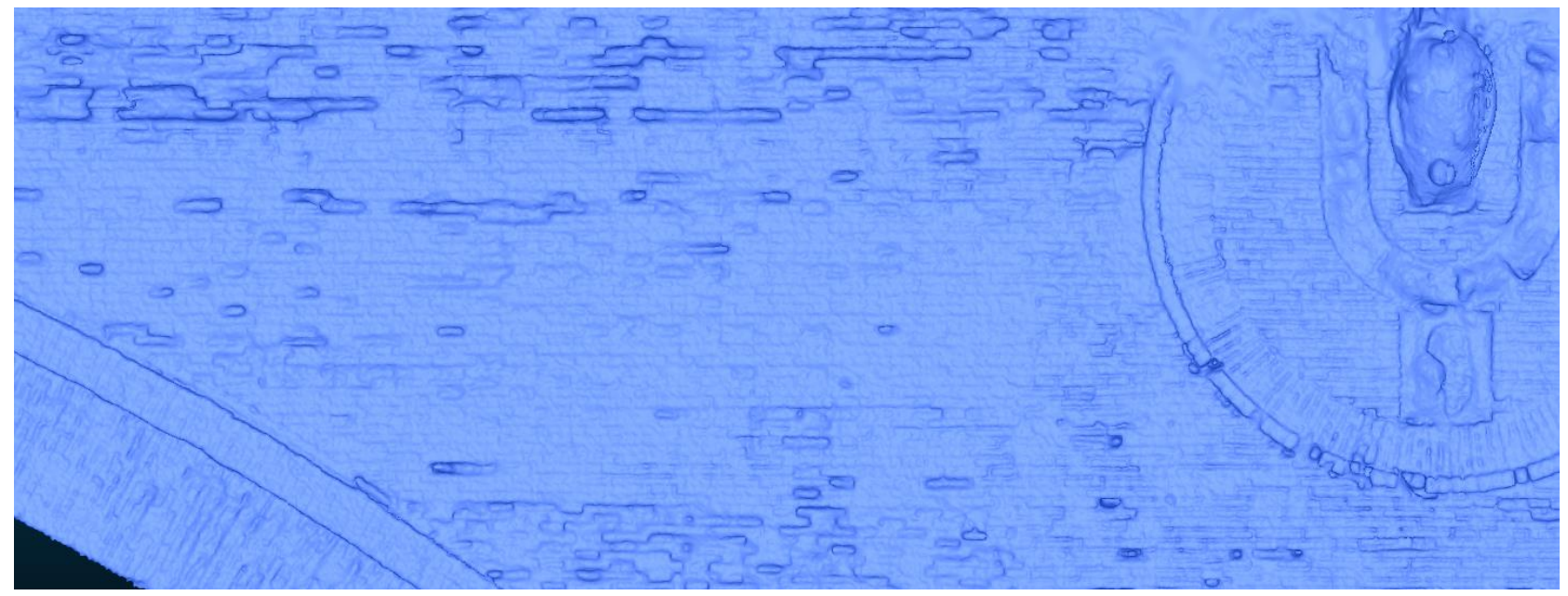

Figure 5 - Particular of the 3D mesh. Red square in figure 6.

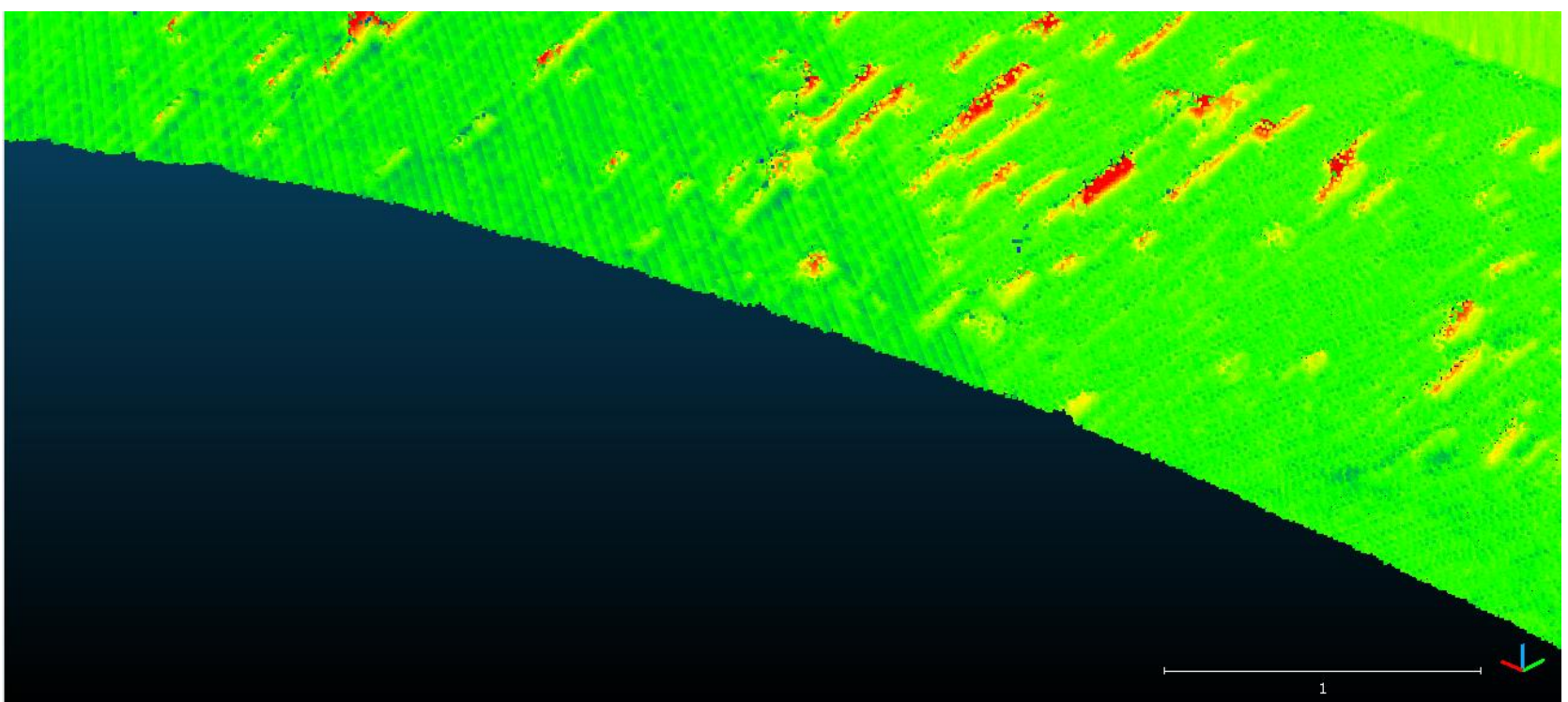

Figure 6 - Surface comparison through Cloud Compare software.

\subsection{Surface comparison, Cloud-to-mesh distance.}

This is a well know and solid technique in TLS inspection software. Surface change is calculated by the distance between a point cloud and a reference 3D mesh (Olsen et al. 2010). To realize the mesh of the bridge CloudCompare software (EDF R\&D, 2011) has been used, in particular the Poissons Surface Reconstruction plug-in (Kazhdan et al. 2006). Once the mesh has been obtained (Fig.7), it has been used as reference surface to perform surface comparison. Figure 7 shows several hotspots identified by the automatic comparison under right bridge span between 2011 and 2017 scans. A manual procedure was also carried out to verify results from automatic comparison. Carrying out comparison analysis no major deformations have been identified. Accordingly to the acquisitions' standard deviation, the comparisons have been carried out considering different displacement thresholds: lower than $2 \mathrm{~cm}$, up to $4 \mathrm{~cm}$, up to 6 and up to $10 \mathrm{~cm}$, accordingly to the acquisitions' standard deviation $<70 \mathrm{~mm}$. In the bottom surface of the bridge's span, both on the left and on the right span. To verify reliability of results a manual approach has also been conducted. Some discrepancies between automatic and manual one have been highlighted. The reasons of why such a false positives have been obtained, has to be identified in the different angle of view under which the scans have been performed in the two different years. As a matter of facts, the performed surface comparison analysis have been carried out by comparing the mesh from year 2011 scanning and the point cloud from year 2017 scanning. The 2011 TLS survey has been carried out using a HDS 6000 laser scanner (Leica Geosystems), while for performing the year 2017 TLS survey, a RIEGL VZ1000 has been used. Through the Geo-referencing procedure, which was made in post processing, a value of 0,067 (m) for residual standard deviation was obtained. For some reasons, mainly attributable to contract and feasibility constraints, further GPS campaigns, to improve accuracy and consequently to reduce residual standard deviation values, has not been performed. In order to mitigate residual standard deviation values obtained by Geo-referencing procedures, a set of weary parameters has been imposed to reconstruct the 2017 
mesh. The final surface, especially for areas that have been scanned under certain angles of view, resulted approximate to the real object surface. Running surface comparison, the coupled effect of high residual standard deviation values and shaded areas, produced misleading results.

\section{CONCLUSONS}

As expected, the comparison between the two TLS surveys, the one made on year 2011 and the one made on year 2017, returned some indications on the bridge structure health. On one hand neither opening and/or closing cracks have not been identified on the two spans nor major structural deformations. On the other, some indications of confined and very local degradation process emerged. In particular, surface comparison analysis, which has been made by using Surface Comparison software (CIT), identified minor surface anomalies. Bricks and building mortar detachments are indeed localized on the spans' bottom surfaces. Natural degradation processes which leaded to bricks and building mortar detachments are indeed constantly acting on the bridge's structures.

On the basis of a preliminary evaluation based on in field evidences, identified damages have been triggered by surficial weathering process. Nevertheless, considering the presence of the maelstrom, nurtured by the constant flux of water acting within the basement under the central pillar, periodical TLS should be planned to perform a long period monitoring.

\section{ACKNOWLEDGEMENTS}

The authors would like to thank the municipality of Pontassieve (Florence, Italy) for the helpful suggestions and the availability on sharing crucial historical information. The author also thanks the Archivio di Stato di Firenze for access to historical and technical documentation. The authors also thanks Alessandro Galeotti for precious support in carrying out in field activities and archive research.

\section{REFERENCES}

Bitelli, G., Balletti, C., Brumana, R., Barazzetti, L., D'Urso, M.G., Rinaudo, F., Tucci, G. Metric documentation of cultural heritage: Research directions from the Italian gamher project (2017) International Archives of the Photogrammetry, Remote Sensing and Spatial Information Sciences - ISPRS Archives, 42 (2W5), pp. 83-90. Cited 8 times. DOI: 10.5194/isprs-archivesXLII-2-W5-83-2017

Bonora, V., Chieli, A., Spanò, A., Testa, P., Tucci, G. 3D Metric-modelling for knowledge and documentation of architectural structures (royal palace in Turin) (2003) International Archives of the Photogrammetry, Remote Sensing and Spatial Information Sciences - ISPRS Archives, 34 (5W12), pp. 60-65.

Castagnetti C., Bertacchini E., Capra A., Dubbini A. Terrestrial Laser Scanning for Preserving Cultural Heritage: Analysis of Geometric Anomalies for Ancient Structures. In: FIG Working Week 2012 - Knowing to Manage the Territory, Protect the Environment, Evaluate the Cultural Heritage, Rome, Italy 2012.

Castellazzi G, D’Altri AM, de Miranda S, Ubertini F 2017 An innovative numerical modelling strategy for the structural analysis of historical monumental buildings Engineering Structures 132 229-248.

Corongiu, M.; Tucci, G.; Santoro, E.; Kourounioti, O. DATA INTEGRATION OF DIFFERENT DOMAINS IN GEOINFORMATION MANAGEMENT: A RAILWAY INFRASTRUCTURE CASE STUDY (2018) International Archives of the Photogrammetry, Remote Sensing and Spatial Information Sciences - ISPRS Archives, Volume XLII-4, pp. 121-127. doi.org/10.5194/isprs-archives-XLII-4-121-2018

EDF R\&D, T.P., 2011. CloudCompare (version 2.3) [GPL software]. Retrieved from http://www.danielgm.net/cc/.

Fregonese, L., Barbieri, G., Biolzi, L., Bocciarelli, M., Frigeri, A., Taffurelli, L. Surveying and Monitoring for Vulnerability Assessment of an Ancient Building. Sensors (Basel) 2013 Aug; 13(8): 9747-9773. Published online 2013 Jul 31. doi: $10.3390 / \mathrm{s} 130809747$

Gigli, G., Mugnai, F., Leoni, L., and Casagli, N.: Brief communication "Analysis of deformations in historic urban areas using terrestrial laser scanning", Nat. Hazards Earth Syst. Sci., 9, 1759-1761, https://doi.org/10.5194/nhess-9-1759-2009, 2009.

Gigli, G. and Casagli, N.: Semi-automatic extraction of rock mass structural data from high resolution LIDAR point clouds, Int. J.Rock. Mech. Min., 48, 187-198, 2011.

Kazhdan, M., Bolitho, M., Hoppe, H., 2006. Poisson Surface Reconstruction. In: Pothier, K., Sheffer, A. (Eds.), Eurographics Symposium on Geometry Processing.

Korumaz, M., Betti, M., Conti, A., Tucci, G., Bartoli, G., Bonora, V., Korumaz, A.G., Fiorini, L. An integrated Terrestrial Laser Scanner (TLS), Deviation Analysis (DA) and Finite Element (FE) approach for health assessment of historical structures. A minaret case study (2017) Engineering Structures, 153, pp. 224-238. DOI: 10.1016/j.engstruct.2017.10.026

Olsen, M.J., Kuester, F., Chang, B.J., Hutchinson, T.C., 2010. Terrestrial Laser Scanning-Based Structural Damage Assessment. Journal of Computing in Civil Engineering 24 (3), 264-272.

Pesci A, Teza G, Boschi E 2015 Laser scanning-based detection of morphological changes of a historical building occurred during a seismic sequence: Method and Case study International Journal of Geomatics and Geosciences 5(3) 427-447.

Riveiro B, et al Fully automatic approach for the diagnosis of masonry arches from laser scanning data and inverse finite element analysis. In: Proceedings of the 10th SAHC. Leuven, Belgium 2016.

Spangher, A., Visintini, D., Tucci, G., Bonora, V. Geomatic 3D modeling of a statue (ALSO) for structural analysis \& risk evaluation: The example of San Giovannino Martelli in Florence (2017) International Archives of the Photogrammetry, Remote Sensing and Spatial Information Sciences - ISPRS Archives, 42 (5W1), pp. 61-68. DOI: 10.5194/isprs-ArchivesXLII-5-W1-61-2017

Revised January 2019 
Tucci, G., Bonora, V., Fiorini, L., Conti, A. The florence baptistery: 3-D Survey as a knowledge tool for historical and structural investigations (2016) International Archives of the Photogrammetry, Remote Sensing and Spatial Information Sciences - ISPRS Archives, 41, pp. 977-984. DOI: 10.5194/isprsarchives-XLI-B5-977-2016

Tucci, G., Bonora, V. From real to $\cdots$ "real". A review of geomatic and rapid prototyping techniques for solid modelling in Cultural Heritage field (2011) International Archives of the
Photogrammetry, Remote Sensing and Spatial Information Sciences - ISPRS Archives, 38 (5W16), pp. 575-582.

Tucci, G., Bartoli, G., Betti, M., Bonora, V., Korumaz, M., Korumaz, A.G. Advanced procedure for documenting and assessment of Cultural Heritage: From Laser Scanning to Finite Element. (2018) IOP Conference Series: Materials Science and Engineering, 364 (1), art. no. 012085, DOI: 10.1088/1757$899 X / 364 / 1 / 012085$ 